\title{
Overcoming the Obstacle of Poor Knowledge in Proving Geometry Tasks
}

ZLATAN MAGAJNA ${ }^{1}$

$\approx$ Proving in school geometry is not just about validating the truth of a claim. In the school setting, the main function of the proof is to convince someone that a claim is true by providing an explanation. Students consider proving to be difficult; in fact, they find the very concept of proof demanding. Proving a claim in planar geometry involves several processes, the most salient being visual observation and deductive argumentation. These two processes are interwoven, but often poor observation hinders deductive argumentation. In the present article, we consider the possibility of overcoming the obstacle of a student's poor observation by making use of computer-aided observation with appropriate software. We present the results of two small-scale research projects, both of which indicate that students are able to work out considerably more deductions if computer-aided observation is used. Not all students use computer-aided observation effectively in proving tasks: some find an exhaustive computer-provided list of properties confusing and are not able to choose the properties that are relevant to the task.

Keywords: Computer-aided observation; Dynamic geometry; OK Geometry; Proof 


\section{Premagovanje ovire šibkega znanja pri geometrijskih dokazovalnih nalogah}

ZlatAN Magajna

$\propto$ Pri dokazovanju v šolski geometriji ne gre le za dokazovanje resničnosti trditve. Pri pouku matematike je bistvo dokazovanja prepričljiva razlaga, zakaj je neka trditev resnična. Učenci doživljajo dokazovanje kot zahtevno; zahteven se jim zdi že pojem dokaza. Dokazovanje trditev o ravninski geometriji vključuje več procesov, najizrazitejša pa sta vizualno opazovanje in deduktivno argumentiranje. Ta procesa sta prepletena, pri čemer pa šibko opazovanje pogosto ovira deduktivno argumentacijo. V članku preučujemo možnost premagovanja ovire učenčevega šibkega opazovanja $\mathrm{z}$ uporabo računalniško podprtega opazovanja $\mathrm{z}$ ustrezno programsko opremo. Predstavljamo izsledke dveh manjših raziskav. Obe pokažeta, da učenci ob uporabi računalniško podprtega opazovanja oblikujejo bistveno več deduktivnih sklepov kot sicer. Vendar pa niso vsi učenci ob uporabi računalniško podprtega opazovanja učinkoviti: nekatere zmede izčrpen nabor lastnosti, ki jih opazi računalniški program, in niso zmožni med lastnostmi izbrati tistih, ki so pomembne za nalogo.

Ključne besede: računalniško podprto opazovanje, dinamična geometrija, OK Geometry, dokaz 


\section{Introduction}

\section{Proving and problem solving}

As a mathematical discipline, geometry is a formalisation of reasoning about shapes that occurs in everyday situations. However, everyday geometry and geometry as a formal discipline are two different systems of practices. The basic difference between them is well known: everyday geometry is essentially empirical, while formal geometry is an axiomatic system. In everyday geometry, the truth of a statement is commonly validated by experience, while in formal geometry the truth of propositions is validated using deductive arguments, usually organised in a proof. The two aspects of geometry - everyday and formal - are also constituent parts of school mathematics. Learning the basic concepts of geometry is, obviously, based on experience; however, virtually all mathematics curricula at some stage include deductive proofs as a means to ascertain the validity of geometric propositions. Herbst (2002) pointed out that the role of proof in school mathematics has changed considerably in the last two centuries. At first, proofs were presented only for the sake of establishing the truth of the considered theorems. Students were not supposed to produce their own proofs, but just to reproduce the proofs presented to them. With time, proofs acquired an additional role: they became a means for developing mathematical reasoning, especially deduction. A novel type of proof-like exercises developed: proof was associated with exercise. Textbooks gradually incorporated didactically elaborated exercises about geometric facts to be proved, and students had to invent their own proofs based on deductive arguments. In current terminology, such exercises can be considered as closed problem situations (Orton \& Frobisher, 1996).

Despite the essential role of proofs in mathematics, students barely accept proofs and proving as a part of 'their mathematics'. Hadas, Hershkowitz and Schwarz (2000) and Raman (2003), among others, reported on several studies of students' perception of proofs in mathematics. These studies indicate that students have difficulty not only in producing proofs, but even in recognising what a proof is. The fact that geometric objects and properties are easily visualised makes proving in the field of geometry both more difficult and easier. The visual nature of geometry facilitates the representation of the studied objects and the presentation of arguments. For this reason, planar geometry has traditionally been considered, and is still considered, an appropriate context for introducing the concept of proof and for developing deductive reasoning (Lingefjard, 2011). On the other hand, since geometric propositions can be easily visualised by simple sketches on a piece of paper, students barely 
find it reasonable to provide deductive arguments for facts that are empirically evident via visualisation. The introduction of dynamic geometry software, an exceptional didactic instrument for the visualisation of geometric objects and properties, makes the visual evidence even more convincing, encouraging students to adhere to empirical argumentation. Thus, it is necessary to clarify the necessity for proofs and the nature of deductive argumentation (Hadas, Hershkowitz, \& Schwarz, 2000).

Demonstrating the truth of a claim is not the only reason, and often not the main reason, for proving in school mathematics. Hanna (2000) compiled the following list of functions of proofs and proving: verification that something is true, explanation why something is true, systematisation of concepts, theorems and various results, discovery of new results, communication of mathematical knowledge, construction of an empirical theory, exploration of the meaning of definitions, and incorporation of known facts into new frameworks. Although proofs are usually presented as a justification (to show the truth of a claim), their real value in the school context is to clarify why something is true (idem). This holds for exemplary proofs (e.g., proofs of relevant theorems) as well as for proofs produced by students when solving proof-like exercises.

There is no general agreement on what a proof is in school mathematics. Stylianides and Stylianides (2009) consider a proof to be an argument for the truth of a statement: the argument should be general, valid and accessible to members of the community involved. The validity of a proof is commonly related to the concept of derivation. In this sense, a proof consists of "a sequence of steps leading from premises to conclusion by way of valid reasoning" (Hanna \& Sidoli, 2007). According to Hanna (2000), a proof should be legitimate and should "lead to real mathematical understanding", as only such a proof is convincing. Pedemonte (2007) lists four characteristics of argumentations and proofs in mathematics: 1) proofs are rational justifications; 2) proofs should convince; 3 ) proofs are addressed to a universal audience; and 4) proofs need to be considered in the context of specific fields (e.g., school geometry). From the perspective of situated cognition, the proof is an artefact that mediates between the individual and social practice (Hemmi, 2010). Due to the different conceptions and various functions of proof, it is not surprising that mathematics teachers develop different subjective theories, so that the way they treat proofs in classrooms ranges from almost ignoring them to including them systematically, from presenting only the key idea of the proof to emphasising the formal derivations (Furinghetti \& Morselli, 2011; Hemmi, 2010; Knuth, 2002). 


\section{Proving and previous knowledge}

Proving a property of a geometric configuration is a mathematical problem. A good paradigm for researching proving as solving problems is the information theory (Kahney, 1993). This approach has been used extensively in researching problem solving in many fields, including mathematics (Schoenfeld, 1985). From this perspective, a problem consists of a set of states called the problem space, a system of rules that define the possible transformation of states, as well as two special states, called the starting point and the goal. Solving a problem means transforming the starting point to the goal with a series of permitted transformations within the problem space. Consider, for example, the problem of proving a fact about a given geometric configuration. The starting point consists of the premises of the configuration, and the goal is, obviously, the claim to be proved. The problem space (of a solver) consists of all configuration-related statements that come to the solver's mind. The transformation rules in geometry are clear: only known facts (known theorems or previously ascertained facts), assumptions and deductive argumentation are allowed.

The problem space is subjective and depends on the solver's knowledge base. High achievers have a rich prior geometric knowledge that is effectively organised into schemas (Chinnappan, 1998). On the other hand, a poor problem space, resulting from poor, confused or disorganised prior knowledge, hinders the solving process. Being capable of deductive argumentation does not help much in proving geometric facts if one is not able to generate an appropriate problem space.

\section{Observation in solving geometry problems}

By an observation, we mean a conscious interpretation of a (visual) perception. Thus, observation refers to concrete properties of visualised geometric configurations. In observing a geometric property, the observer relates the visual perception to his/her understanding of the involved concepts and properties. Thus, observation is associated with the observer's knowledge.

An observation of a property may occur by chance, but usually, when solving geometry tasks, observing is an active process. Observation occurs in an interpretative context and can be more or less focused. We do not discuss here various observation strategies in solving geometry problems, as we take it for granted that a good solver is aware of the importance of non-focused observation and, on the other hand, is able to identify which properties are relevant to specific problems and focus on them during observation.

Observing is an essential process in learning geometry. Jahnke (2007) suggested that the introduction of the concept of proof to pupils should be 
based on experiential observation, for this is the pupils' natural way of establishing the truth of geometric facts. The underlying idea of this approach is: in a context where events are highly or completely predictable, observations are also predictable. Since geometry is a predictable context par excellence, proofs can be thought of as an effective substitute for observation. For example, one can prove that in a triangle the congruence of two of the triangle's sides implies the congruence of triangle's angles opposite to the congruent sides. Thus, there is no need to observe and check the congruence of the base angles each time we encounter an isosceles triangle. The proof is a way for establishing the truth of a claim once and for all.

The role of observation in proving geometric facts is quite complex. In theory, the proof of a geometric fact should not depend on the observation of a visual representation (Hanna \& Sidoli, 2007). In practice, however, especially in school geometry, visual representations are essential: sometimes their purpose is to illustrate a concept or a claim, sometimes they serve as informal justifications, and there are situations where a proof can be reduced to a 'visual argument' (not just observation) (Hanna \& Sidoli, 2007). When solving geometry problems, visualisation is a thinking aid for representing geometric facts (which can be true or false). An observer may or may not be aware of a property related to a represented configuration. Furthermore, a property that is observed may or may not be true. The awareness of an observed property is thus associated with various degrees of certainty of its truth. The degree of certainty ranges from very hypothetical to absolute certainty. Observing thus allows the student to become aware of properties, while also offering some degree of certainty. Let us recall the case of the isosceles triangle. One observer may not be aware that its base angles are congruent, whereas someone else may perceive the angles as being congruent and consider this as a hypothesis. If measuring the angles shows the same angle size, this raises the degree of certainty that the base angles are congruent. Finally, someone may consider, on the basis of previous knowledge, the congruence of base angles in isosceles triangles as unquestionably true.

The role of observation in solving geometric problems can also be explained in terms of the information paradigm. Given a geometric problem, the solver first constructs a problem space, i.e., a set of properties related to the geometric problem. To solve a problem means to connect a subset of properties in a proper way. Toulmin's model of argumentation (Pedemonte, 2007; Fujita, Jones, \& Kunimune, 2010) provides further insight into this process. The solver needs (besides a strategy) some guidance when moving in the problem space. In order to take a property into consideration in constructing a proof, one needs some guarantee that, to be possibly considered in the proof, the property 
holds. In the case of geometric problems, the solver uses observation to obtain hypothetical properties that could be eventually be used in the solution (or proof). If the solver has some doubts whether a property (claim) is true, a more careful or elaborated observation may be used in order to reject the claim or to provide an additional guarantee for the claim. In the case that the hypothesis appears to be true and is of use in the solution to the problem, the solver should, at some stage, provide a backing, i.e., convincing (unquestionable, deductive) arguments for the hypothesised claim. A similar approach was used by Nunokawa (2010), who stresses the dynamic nature of the problem space. According to him, the construction of the problem space is, to some extent, parallel to the justification of the observed properties: in fact, it is the justification of an observation that often leads to new focuses and to observation of properties that otherwise would not be noticed.

\section{Computer-Aided Observation - OK Geometry}

Solving a geometric problem requires the construction of an appropriate problem space. It is essential that, at some stage of proving, the solver is aware of the properties - established or hypothesised - that could possibly be used in building up a proof. Note that the solver's problem space is, in general, not static: during the proving process new insights may lead to new focuses, while previously considered ones are ignored. However, not being aware of the relevant properties at any stage of the proof is an obstacle to building up proofs and, consequently, to learning to prove. The reason for not being aware of a property (not observing it) may be simply 'not paying attention' or it may be poor knowledge that prevents an appropriate interpretation of a perception. In any case, this lack of awareness prevents the solver from connecting facts, proving facts and upgrading proving skills.

In order to research the nature of this obstacle, a research tool called OK Geometry was developed by the author. ${ }^{2}$ In simple terms, OK Geometry is a tool for the computer-aided observation of dynamic geometric constructions. As opposed to static geometric constructions made by paper and pencil, dynamic geometry constructions are computer representations that allow the dragging of non-constructed objects and the dynamic display of the constructed objects. Dynamic geometry systems are widely used in school mathematics. Given a dynamic construction, obtained by some of the widely used dynamic geometry systems, OK Geometry provides a list of properties related to the studied construction (together with their visual representations). OK Geometry does not

OK Geometry is available at http://z-maga.si/index?action=article\&id $=40$ 
prove facts, it only lists the properties that are detected by the software. Due to the method of observation used, the possibility of an observational error is rather remote. In the school setting, the list of observed properties can be used for various purposes, e.g., the exploration or connecting of facts. We shall focus here on just one purpose: proving facts.

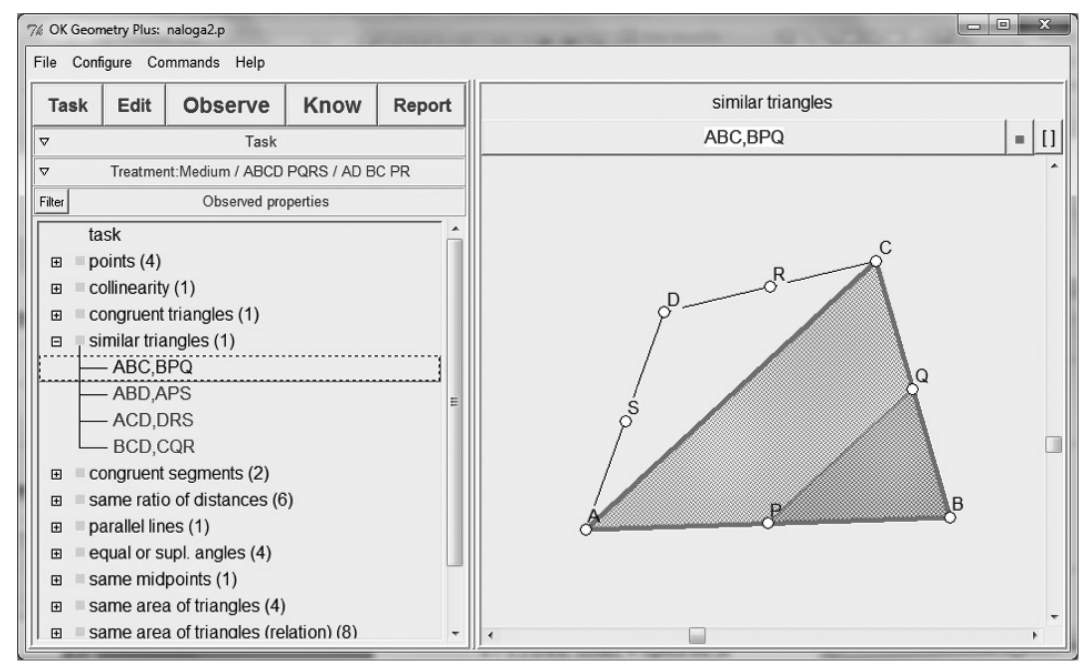

Figure 1. Using computer-aided observation in a proving task.

Computer-aided observation assures that solvers notice a variety of properties of the studied geometric configuration, including those that are relevant to the solution of the geometric problem. The list is presented in a structured way so that the various properties are easily retrieved and visualised (Figure 1). However, even in simple geometric configurations, the computer-provided list of properties can be rather extensive, for it includes many trivial properties and properties that are irrelevant to the solution of the problem. Evaluation of the list of properties should be directed by the aim or by the clear idea of what the list of properties was created for: in this case, the need to solve the given problem. The solver needs to decide which properties from the computer-provided list are trivial or probably irrelevant to the solution, and which are possibly related to the solution. The latter are then organised into a solution/proof.

OK Geometry allows a further simplification of the above described proving process (Figure 2). In the simplified form, the proving task consists of a claim to be proved together with a list of 'observed' properties to be used in the proof. The student needs only organise the given properties into a proof and provide arguments for the claims in the proof. 


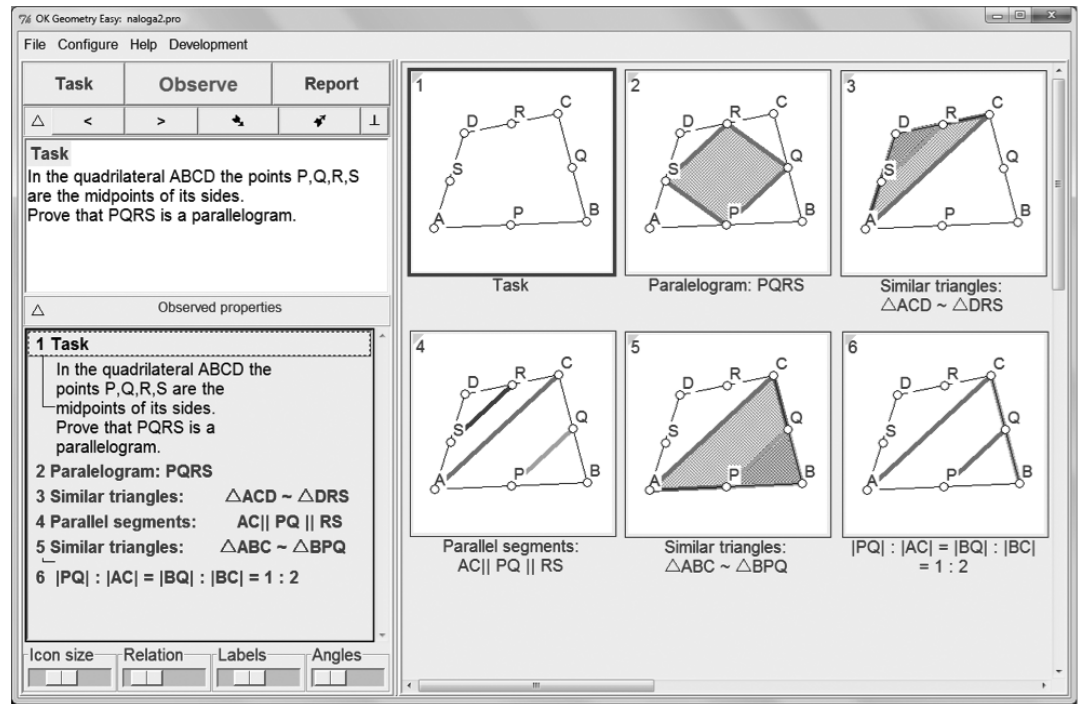

Figure 2. A proving task with given selected properties.

\section{Research Question}

Observing is unquestionably an important cognitive process that should be developed during mathematics education. Proving in geometry involves observing, especially when the solver constructs the problem space related to the task. Obviously, a poor problem space is an obstacle to working out deductive arguments related to the solved task.

We conjecture that computer-aided observation can extend students' problem space related to geometry proving tasks and, consequently, can facilitate the expression of deductive argumentations.

Put simply, we conjecture that in solving geometry proving tasks, computer-aided observation can help students (novices) to overcome the obstacle of poor observation ability. In such tasks, computer-aided observation can be a facilitator for expressing deductive reasoning.

In the sections that follow, we present the results of two small-scale research projects.

\section{The First Research Project}

The participants were six above-average students aged 15 years, all of whom were attending the first year of gymnasium (general upper secondary school). They had been studying planar geometry in the months directly 
preceding the research. The students worked on two problems:

1. The quadrilateral task (Figure 1 left). In the quadrilateral $\mathrm{ABCD}$, the points $\mathrm{P}, \mathrm{Q}, \mathrm{R}, \mathrm{S}$ are the midpoints of its sides.

1a. Write down a list of all of the properties (not explicitly mentioned in the task) that you observe. For each property, if possible, explain why it is true.

1b. Prove that PQRS is a parallelogram.

2. The trapezium task (Figure 1 right). In the trapezium $\mathrm{ABCD}$, let $\mathrm{E}$ be the intersection of diagonals $\mathrm{AC}$ and $\mathrm{BD}$.

2a. Write down a list of all of the properties (not explicitly mentioned in the task) that you observe. For each property, if possible, explain why it is true.

2b. Prove that the triangles AED and BCE have the same area.
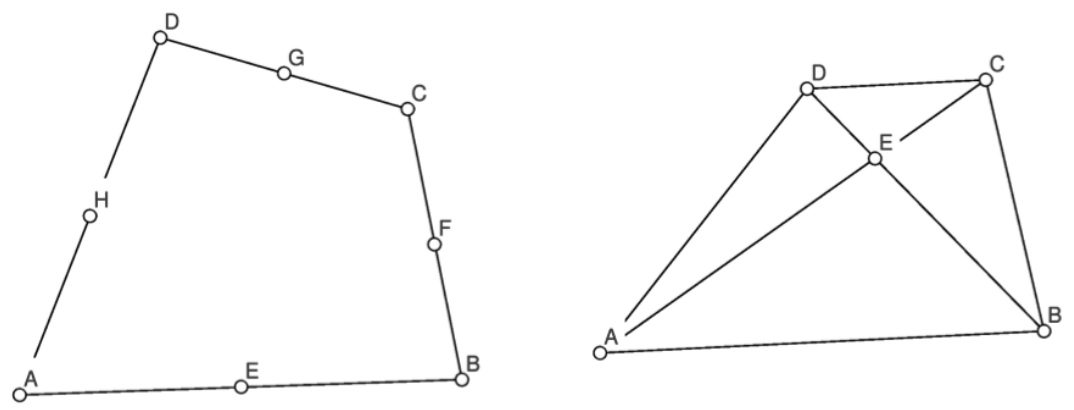

Figure 3. The illustrations for the quadrilateral and the trapezium tasks.

The students first worked individually with paper and pencil (i.e., in the way they were used to solving geometry problems). They solved the tasks 1a, $1 \mathrm{~b}, 2 \mathrm{a}$, and $2 \mathrm{~b}$ one by one, spending approximately 5-10 minutes on each task.

In the second phase, the same students worked on the same four tasks (1a, 1b, 2a, 2b), except that:

1. In tasks $1 \mathrm{a}$ and $2 \mathrm{a}$, they used OK Geometry to obtain a computer-provided list of properties. They only had to select the properties they considered interesting and non-trivial. They were also asked to try to prove the selected properties. Tasks $1 \mathrm{~b}$ and $2 \mathrm{~b}$ were worked out with paper and pencil or using OK Geometry after tasks 1a and $2 \mathrm{a}$, respectively.

2. The students worked in pairs (they were supposed to work alone, but as OK Geometry revealed the properties of the studied configuration the students could not resist discussing them with the student next to them). 
The students' solutions were analysed as follows. First, all non-trivial geometric properties of the two configurations (Figure 3) within the reach of the students were identified: these were considered the 'canonical list of properties' of each configuration. The list comprised claims about congruent angles, parallel lines (in the quadrilateral task), congruent triangles, similar triangles, etc. Then, the students' answers to each task were considered. For each property in the 'canonical list of properties' of a configuration, it was established whether the student noted the property and whether s/he gave reasonable arguments for its validity. The trivial claims in the answers (e.g. 'the quadrilateral has four sides', 'the bases of trapezium are parallel') were ignored. Table 1 displays the percentage of properties (relative to the 'canonical list of properties') that were identified and the percentage of those for which the students gave reasonable arguments in the first (paper and pencil) phase and in the second (OK Geometry) phase.

Table 1. Observed and proved properties for various observational methods. The percentages refer to the canonical list of properties related to each task.

\begin{tabular}{ccccc}
\hline \multirow{2}{*}{ Task } & \multicolumn{2}{c}{ Paper and pencil } & \multicolumn{2}{c}{ OK Geometry } \\
\cline { 2 - 5 } & Observed facts & Proved facts & Observed facts & Proved facts \\
\hline The trapezium task & $0 \%$ & $0 \%$ & $73 \%$ & $40 \%$ \\
\hline The quadrilateral task & $6 \%$ & $4 \%$ & $48 \%$ & $24 \%$ \\
\hline
\end{tabular}

In the first phase, the students were virtually unable to identify any non-trivial properties, and, obviously, did not prove these properties. The high percentage of observed facts in the second phase is not surprising, as the students only had to select among the properties provided by the computer. In the trapezium case, for example, they 'missed' $27 \%$ of relevant properties (they either considered them to be trivial/irrelevant or they did not understand them). What is striking is that they were able to prove approximately half of the facts they did not even notice before. Obviously, being aware of some facts helped them to prove other facts.

\section{The Second Research Project}

The participants in this research were 38 prospective mathematics teachers at the beginning of their fourth year of study. During their university study, they attended some courses in advanced geometry.

Each student was asked to solve four tasks, which shall be referred as Task $1,2,3$ and 4 . Note that the order in which the tasks were presented varied from 
student to student. Each task contained a situation and a property to be proved.

The four problem tasks (not listed here) to be solved by the participants were comparable in form and difficulty to tasks $1 b$ and $2 b$ in the first research project. The tasks were solved in three phases:

Phase 1. The students were asked to work individually using paper and pencil on the first two tasks, using approximately five minutes for each task.

Phase 2. In the second phase, the students solved the first three problems individually using computer-based observation. Using OK Geometry, their task was to import a ready-made dynamic construction, to generate a list of properties, and to select the properties to eventually be used in the proof. They then tried to work out the strategy of the proof by organising the selected properties into an appropriate order. Finally, they tried to provide arguments for each step in the proof. OK Geometry served as an observational tool and as a tool for organising and documenting their work. The students had a limited time (15 minutes) to complete all three tasks. If a student claimed that $\mathrm{s} / \mathrm{he}$ had already solved a problem in Phase 1 , his/her solution of Phase 1 was also accepted for Phase 2, and s/he could skip the task.

Phase 3. In the third phase, each student solved all four tasks individually in the same order as in the previous phases. In this phase, they solved the problems using OK Geometry, but instead of an extensive list of properties related to each task, they used a short list of selected properties to be used in a proof. The students only had to work out the strategy of a proof by organising the selected properties into an appropriate order, while also providing arguments for each step of the proof. As in the previous step, they worked individually on computers, also using OK Geometry to document their work. They had a limited time (20 minutes) to complete all four tasks; however, none of the students worked out more than three tasks. The students were allowed to claim they had already solved a problem in a previous phase and skip to the next problem; in this case, the solution of the previous phase was also accepted in Phase 3.

Table 2. The plan of task presentation in the second study.

\begin{tabular}{llccc}
\hline \multirow{2}{*}{$\begin{array}{l}\text { Phase } \\
\text { Time }\end{array}$} & Method & \multicolumn{3}{c}{ Order of the presented tasks } \\
\cline { 2 - 4 } & Group 1 & Group 2 & Group 3 \\
\hline $\begin{array}{l}\text { Phase 1 } \\
10 \text { min. }\end{array}$ & Paper and pencil & 1,2 & 1,3 & 1,4 \\
\hline $\begin{array}{l}\text { Phase 2 } \\
15 \text { min. }\end{array}$ & $\begin{array}{l}\text { Complete list of properties } \\
\text { (computer-aided observation) }\end{array}$ & $1,2,3$ & $1,3,4$ & $1,4,2$ \\
\hline $\begin{array}{l}\text { Phase 3 } \\
20 \text { min. }\end{array}$ & $\begin{array}{l}\text { Selected list of properties } \\
\text { (computer-aided observation) }\end{array}$ & $1,2,3,4$ & $1,3,4,2$ & $1,4,2,3$ \\
\hline
\end{tabular}


Using this arrangement, all of the problems (except Problem 1) were solved by some students first by paper and pencil, then (if not solved) using the computer-generated list of observations, and then (if still not solved) by making use of selected properties. The same problem was solved by other students initially by computer-generated observations, and then (if not solved) by making use of the list of selected properties to be used in the proof.

For each task, the various possible strategies of solutions were divided into the same number of steps (claims). For each proposed solution, the following points were considered:

- whether the overall strategy (the basic idea) of the solution was correct, - the number of relevant properties (solution steps) for which a student gave correct arguments,

- the number of incorrect claims (i.e., observations that were false),

- the number of claims (proved or unproved) that were not relevant to the solution of the problem.

The results are summarised in Figure 4 and Figure 5.

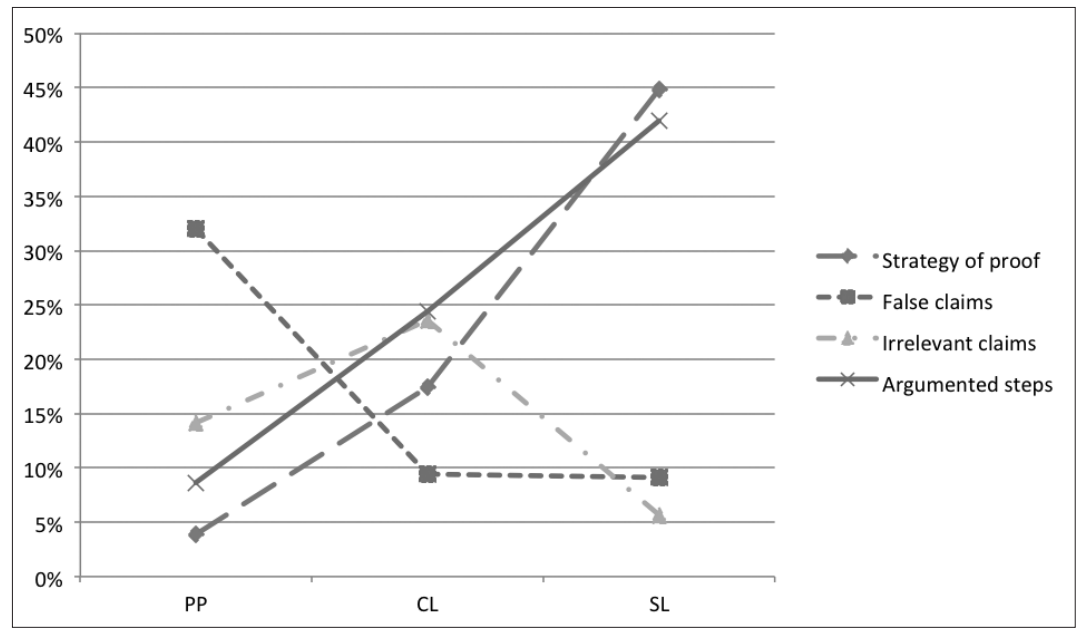

Figure 4. The structure of claims in the solutions of the proving tasks for various observational methods (PP - paper and pencil, CL - complete list of properties obtained by computer-aided observation, SL - selected list of properties obtained by computer-aided observation).

Let us first consider the results shown in Figure 4. The students solved the geometric problems in three modalities: 1) without any help, just using 
paper and pencil (PP); 2) provided with an extensive computer-generated list of properties (CL); and 3 ) provided with a reduced list of properties to be used in the proof (SL). When working with paper and pencil (PP), the students found the solution strategies for a total of only approximately $4 \%$ of the tasks, and provided an argument for approximately $9 \%$ of the solution steps. The respective results rose to $17 \%$ and $24 \%$ when an extensive list of properties was provided (CL). Providing the students with a list containing only essential properties (SL) produced even better results: $45 \%$ and $42 \%$, respectively.

It is not surprising that more tasks are solved if the students are provided with an extensive list of properties, and that even more tasks are solved if they are provided with a list of essential properties to be considered in the proof. This is why authors of textbooks often add some hints to proving exercises in order to make them easier. However, we considered this phenomenon from another perspective: poor observation is an obstacle in proving facts in geometry, and, by extension, hinders the developing and demonstrating of deductive argumentation. Observing is unquestionably an essential process in proving, one that should be promoted and emphasised. However, there is no reason for poor observation to prevent students developing argumentation abilities, and it appears that computer observation may help students in this respect.

Figure 4 also indicates that poor observation manifests in two ways: 1) not seeing (not being aware) of relevant properties, and 2) observing 'false' properties, i.e., properties that do not hold. On average, when working with paper and pencil (PP), the students considered and gave arguments for approximately $9 \%$ of essential properties and $14 \%$ of irrelevant properties. Approximately $33 \%$ of the properties the students claimed or hypothesised to be true (whether they provided some arguments for them or not) were false. Obviously, there is nothing wrong with considering false or irrelevant properties (although sometimes they may be a symptom of poor expertise): considering false properties may, in fact, be a good source of new conceptual knowledge. On the other hand, false and irrelevant claims hinder the proving process. Figure 4 indicates, as is reasonable to expect, that if the students are provided with an extensive list of properties (CL), the number of irrelevant claims increases and the false claims, though still present, decrease in number. The reason for the presence of false statements will be explained shortly. 


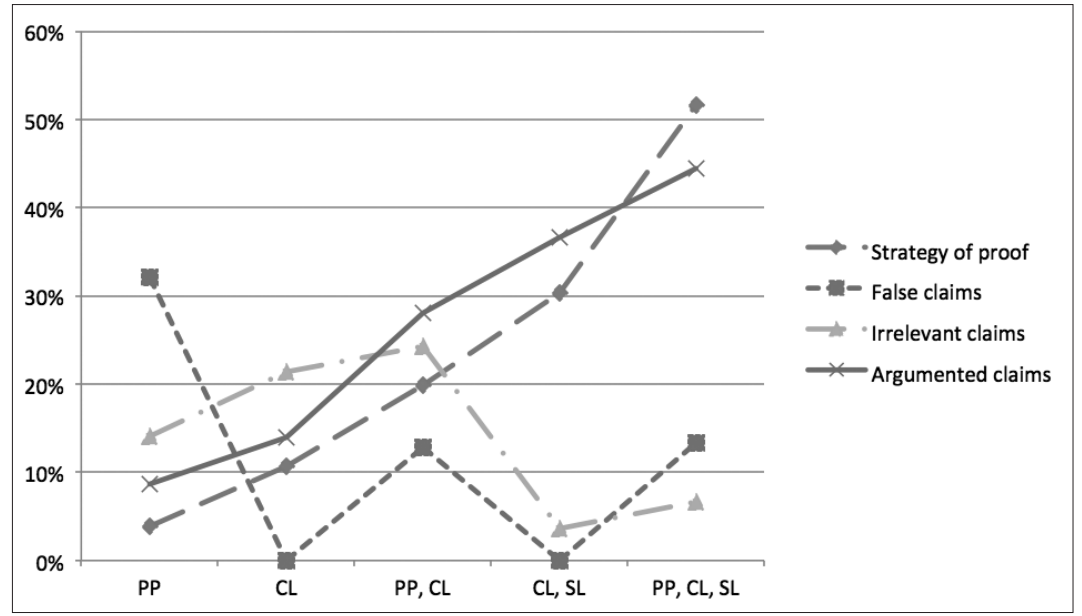

Figure 5. The structure of the claims in the solutions of the proving tasks for various combinations of observational methods (PP - paper and pencil, CL - complete list of properties obtained by computer-aided observation, SL - selected list of properties obtained by computer-aided observation).

Figure 5 presents some aspects of solving geometric tasks for selected combinations of observation methods. As already explained, paper and pencil (PP), a complete computed-provided list of properties (CL) and a selection of essential properties (SL) were associated with various degrees of help in solving proving problems. Obviously, combining two or more of these methods (i.e., one method after another in succession) improved success, as more time was available for finding a solution. One interesting phenomenon is the persistence of false claims when the paper and pencil method was followed by computeraided observation: in some cases, the student tried to prove a claim even after computer-aided observation did not confirm its correctness. Perhaps this can be explained as fixation or confirmation bias, but we prefer to interpret it as the student's need to explore the configuration by themselves and achieve a personal conviction. The question as to whether it is profitable to combine various observation methods, and how to combine them, requires further investigation.

\section{Conclusions}

We have presented the results of two small-scale studies on the role of observation in solving geometric problems that require deductive argumentation. Although there are certain validity issues in these studies (e.g., the relatively 
short time for paper and pencil work), the results indicate that computer-aided observation can help students to build up an appropriate problem space related to geometry tasks. Consequently, this facilitates the expressing of deductive argumentations in geometry proving tasks. Since a poor problem space may also result from poor observation ability, computer-aided observation can, to some extent, overcome the obstacle of poor observation in solving such tasks.

Most of the participants in the studies used computer-aided observation effectively, but not all and not always. Some found the large number of properties identified by the computer software confusing, even though the properties were presented in a structured way. Some focused their attention rigidly on a particular property that they were convinced would lead to the solution even though the property was not on the computer-provided list (and was false). Evidently, solving problems using computer-aided observation requires the adoption of appropriate strategies, especially if the solver's knowledge is poor. An expert in the field knows which type of properties to look for in specific problems, while a novice has to develop a technique or strategy for selecting the potentially relevant properties. The novices' strategies for solving geometry proving tasks using computer-aided observation are certainly worth researching in the future, as they may find suitable other strategies besides "working forwards" or "working backwards".

Observation is an essential process in building up proofs, as it provides the necessary hypotheses that need deductive backing. In this sense, observation is a prerequisite for deductive argumentation. Current school-oriented software tools for learning planar geometry (dynamic geometry systems) are powerful tools for visualising and checking properties. In working out proving tasks, such software can help students to check observed properties that serve as hypothesised steps in the proof (Mariotti, 200o). However, if the solver is not able to identify the relevant properties to be used in a proof, dynamic geometry software will not be of any help, as the solver does not know which properties to check and, eventually, use in deductive argumentation. Poor observation ability is thus an obstacle to developing deductive reasoning. The two pilot studies indicate that computer-aided observation may be used to overcome the obstacle of poor observation and enable students to make deductions.

\section{References}


activities: a case of cognitive unity? In M. F. Pinto \& T. F. Kawasaki (Eds.), Proceedings of the 34th Annual Conference of the International Group for the Psychology of Mathematics Education, Vol. 3 (pp. 9-16). Belo Horizonte, Brazil.

Furinghetti, F., \& Morselli, F. (2011). Beliefs and beyond: hows and whys in the teaching of proof.

Zentralblatt für Didaktik der Mathematik, 43, 587-599.

Hadas, N., Hershkowitz, R., \& Schwarz, B. (2000). The role of contradiction and uncertainty in promoting the need to prove in dynamic geometry environments. Educational Studies in Mathematics, 44, 127-150.

Hanna, G., \& Sidoli, N. (2007). Visualization and proof: a brief survey of philosophical perspectives, Zentralblatt für Didaktik der Mathematik, 39, 73-78.

Hanna, G. (2000). Proof, Explanation and Exploration: an Overview. Educational Studies in Mathematics, 44, 5-23.

Hemmi, K. (2010). Three styles characterising mathematicians' pedagogical perspectives on proof. Educational Studies in Mathematics, 75, 271-291.

Herbst, P. G. (2002). Establishing a custom of proving in American school geometry: Evolution of the two-column proof in the early twentieth century. Educational Studies in Mathematics, 49, 283-312. Jahnke, H. N. (2007). Proofs and Hypotheses. Zentralblatt für Didaktik der Mathematik, 39(1-2), 79-86.

Kahney, H. (1993). Problem Solving: Current Issues. Buckingham: Open University Press.

Knuth, E. J. (2002). Teachers' Conceptions of Proof in the Context of Secondary School Mathematics. Journal of Mathematics Teacher Education, 5, 61-88.

Lingefjärd, T. (2011). Rebirth of Euclidean geometry? In L. Bu \& R. Schoen (Eds.), Model-Centered Learning: Pathways to Mathematical Understanding Using GeoGebra (pp. 205-215). Rotterdam: Sense Publishers.

Mariotti, M. A. (2000). Introduction to proof: The mediation of a dynamic software environment. Educational Studies in Mathematics, 44, 25-53.

Nunokawa, K. (2010). Proof, mathematical problem-solving, and explanation in mathematics teaching. In G. Hanna (Ed.), Explanation and proof in mathematics. Philosophical and educational perspectives (pp. 223-236). Berlin: Springer.

Orton, A., \& Frobisher, L. J. (1996). Insights into Teaching Mathematics. London: Cassel.

Pedemonte, B. (2007). How can the relationship between argumentation and proof be analyzed? Educational Studies in Mathematics, 66, 23-41.

Raman, M. (2003). Key ideas: what are they and how can they help us understand how people view proof? Educational Studies in Mathematics, 52, 319-325.

Schoenfeld, A. H. (1985). Mathematical Problem Solving. San Diego: Academic Press.

Stylianides, A., \& Stylianides, G. J. (2009). Proof Constructions and Evaluations. Educational Studies in Mathematics, 72(2), 237-253. 


\section{Biographical note}

Zlatan Magajna is an assistant professor for didactics of mathematics at the Faculty of Education University of Ljubljana. After studying theoretical mathematics at the University of Ljubljana he worked for many years as a development engineer in the field of computer aided design. He received his $\mathrm{PhD}$ in the field of mathematics education at the University in Leeds. His main fields of research are: mathematics in out of school and working environment, using computer technology at teaching mathematics. He also works on mathematics curriculum at primary, technical and vocational level; and also analyzing international comparative mathematics acchievement studies. 